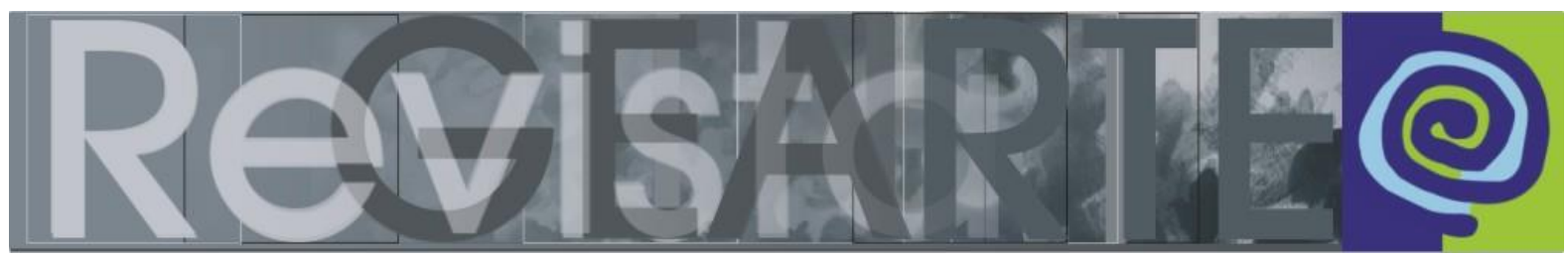

ISSN 2357-9854

\title{
Para pensar o horizonte da arte e da educação na contemporaneidade
}

\section{Carmen Lúcia Capra (Universidade do Estado do Rio Grande do Sul — UERGS, Montenegro/RS, Brasil)}

\author{
Daniel Bruno Momoli (Universidade Alto Vale do Rio do Peixe - UNIARP, \\ Caçador/SC, Brasil e Faculdade Senac, Caçador/SC, Brasil)
}

\section{Luciana Gruppelli Loponte (Universidade Federal do Rio Grande do Sul — UFRGS, Porto Alegre/RS, Brasil)}

\begin{abstract}
RESUMO - Para pensar o horizonte da arte e da educação na contemporaneidade - Este artigo pretende problematizar a relação entre as artes visuais e a educação básica, levando em conta a emergência de novos modos de habitar a escola, como os surgidos a partir de ocupações em escolas públicas por estudantes no Brasil desde o ano de 2015. Acredita-se que tanto a arte quanto a educação, compreendidas como campos expandidos e abertos de pensamento, podem aprender mutuamente outros modos de enfrentar as urgências de nosso tempo em relação à educação básica em território brasileiro, com atenção especial às artes visuais nesse contexto. Para a discussão proposta, tomamos como interlocutores teóricos filósofos como Michel Foucault, Giorgio Agamben e Jaques Rancière, entre outros, interrogando sobre a arte que se tem levado para a escola e sobre a experiência com as artes visuais que lá se tem desenvolvido. Entendemos que a escola de hoje exige modos de agir e de se conduzir as artes visuais que atendam ao que se passa no presente da existência comum e partilhada entre os seus habitantes.
\end{abstract}

PALAVRAS-CHAVE

Arte. Educação. Escola. Atitude estética. Política.

ABSTRACT - To thinking the horizon of art and contemporary education - This article aims to discuss the relationship between the visual arts and basic education, taking into account the emergence of new ways of inhabiting schools, such as those that have arisen from occupations in public schools by students in Brazil since 2015. It is believed that both art and education, understood as expanded and open fields of thought, can mutually learn other ways of facing the urgent needs of our time as regards basic education in Brazil, with special attention to the visual arts in this context. For the proposed discussion, we have taken as theoretical interlocutors philosophers such as Michel Foucault, Giorgio Agamben and Jacques Rancière, among others, raising questions about the form of art which has been taken to schools and what kind of artistic experience has been developed in them. We understand that schools today require ways to act and to conduct oneself within the visual arts that meet what currently takes place in the common experience shared by their inhabitants.

KEYWORDS

Art. Education. School. Aesthetic atitude. Policy.

Michel Foucault, em um de seus textos, propõe uma análise à pergunta feita por Immanuel Kant - Was ist Aufklärung? - e aponta para questões em torno de um conjunto de situações de seu tempo e questiona: "o que se passa hoje? O que se passa agora? E o que é este "agora" no interior do qual nós somos uns e outros?". O

CAPRA, Carmen Lúcia; MOMOLI, Daniel Bruno; LOPONTE, Luciana Gruppelli. Para pensar o horizonte 179 da arte e da educação na contemporaneidade.

Revista GEARTE, Porto Alegre, v. 3, n. 2, p. 179-191, maio/ago. 2016.

Disponível em: http://seer.ufrgs.br/gearte 
autor se utiliza do próprio pensamento para provocar uma interrogação filosófica que "problematiza a relação com o presente, o modo de ser histórico e a constituição de si próprio" (FOUCAULT, 2005, p. 345).

Em sua interrogação, Foucault aponta para uma ruptura ou um desvio em relação a um modo de pensar a partir do século XVIII, desafiando o leitor a encarar a modernidade mais como atitude do que como um período histórico. O pensamento que se produziu a partir dessa ruptura é, para Foucault (2005, p. 341), uma atitude, "um modo de relação que concerne à atualidade (...) uma maneira de pensar e de sentir, uma maneira também de agir e de se conduzir".

A atualidade de tal pensamento permite tensionar as investigações no campo da arte e da educação a partir de urgências de nosso tempo e problematizar simultaneamente a nossa relação com o presente. Operar com esta pergunta na relação entre arte e educação, no domínio do ensino da arte ou para além dele, nos leva a fazer algumas perguntas, tais como: que arte entra ou impacta na escola? Quais as promessas da arte e seu ensino para a educação básica?

O horizonte dessas perguntas é desenhado por interesses que vão para além de uma busca por "metodologias" de uma "boa aula" de arte. Assim, neste artigo, nos colocamos em uma perspectiva de produzir encontros para além daqueles que já são conhecidos entre arte e educação. Acreditamos que tanto a arte quanto a educação, compreendidas como campos expandidos e abertos de pensamento, podem aprender mutuamente outros modos de enfrentar as urgências de nosso tempo em relação à educação básica, com atenção especial às artes visuais. Com esse propósito, pretendemos problematizar esta relação, tendo como foco as artes visuais e suas possibilidades, levando-se em conta a emergência de novos modos de se habitar a escola, como os surgidos a partir de ocupações em escolas públicas por estudantes no Brasil desde 2015.

Além disso, pretende-se iniciar uma análise do regime estético da obra de arte em relação à ensinada na escola, visto que mesmo que a época estética da arte esteja no passado, de alguma forma, o regime estético se mantém atuante. 


\section{As artes visuais na educação básica: uma urgência do nosso tempo}

Encontramos na escola várias interpretações da relação entre arte e educação, por exemplo, um uso instrumental como técnica, como reprodução de ideias préconcebidas, ou ainda, regida por datas comemorativas. Podemos encontrar também a cópia ou a releitura dos "artistas famosos", o reforço de uma arte como criatividade controlada ou de um livre fazer descompromissado. Entretanto, também encontramos experiências pedagógicas em ensino de arte que fogem a esse pensamento conformado, explorando outras potencialidades das artes na educação.

Todas essas questões já foram bastante discutidas em diversas publicações (TOURINHO, 2003; MARTINS, 2011). Ainda é importante continuarmos revisitando essas discussões, já que a escola parece impassível a elas. No entanto, é preciso ampliar as possibilidades entre artes visuais e educação básica para ultrapassar certa "moral de escolarismo" (JÓDAR; GÓMEZ, 2004). Uma moral afinada com uma certa pedagogia constituída sob a expansão da escolarização obrigatória, em que qualquer problema deve ter uma solução previamente conhecida. É o necessário distanciamento de uma sensatez pedagógica que se movimenta no circuito das respostas já dadas a perguntas já conhecidas. O que nos interessa é uma pedagogia não escolarista, centrada na modificação daquilo que somos e na produção do novo.

Como a escola pode encontrar-se com a arte e de que arte a escola, repleta de crianças e jovens desse tempo, precisa? Seríamos ainda modernistas demais, como já alertava Efland (2008), reforçando apenas o ensino de arte como o aprendizado de conteúdos da linguagem visual?

A partir de 2015, emergiram movimentos de estudantes secundaristas brasileiros que ocuparam escolas públicas, reivindicando questões básicas como: organização curricular, garantia da merenda, melhores condições de trabalho aos professores, uso do material didático, etc. Chama atenção o quanto esses alunos buscam na arte modos de tratar o que estão pensando e vivendo, por meio da produção de fanzines, performances, festivais de música, saraus, vídeos. Por meio das redes sociais manejadas habilmente pelos estudantes, tivemos acesso a alguns 
modos pelos quais eles encontraram formas novas de organização e convivência na escola, recriando os tempos e espaços escolares.

Em Porto Alegre (RS), para citar exemplos, alunas e alunos criaram uma rede para ativar a circulação de informações: "Ocupa Tudo Julinho"; "Ocupa Ernesto Dornelles"; "Ocupa Emilio" são algumas. Nelas, as imagens descreviam o dia a dia das ocupações e as formas de organização que foram sendo encontradas e ou criadas pelos jovens. Os estudantes recriaram aulas e espaços escolares a partir de assuntos até então distantes da escola, como gênero - a partir de murais feministas criados em algumas ocupações - e violência e transporte público - a partir de diálogos e encontros com representantes de movimentos sociais e ou de entidades sociais de representação.

Enquanto isso, professores arraigados a ideais modernistas seguem apegados a grades curriculares, a disciplinarização, a ordens pré-estabelecidas e, em relação a aulas de arte, seguem exigindo uma aprendizagem sobre a vida de artistas, características de movimentos artísticos ou a um fazer artístico vazio de criação, com pouca conexão com os problemas do mundo e, sobretudo, do mundo próximo.

A luta pela obrigatoriedade do ensino de arte nos currículos da educação básica brasileira nos tomou bastante tempo e, sem dúvida, foi uma conquista fundamental (RICHTER, 2008). Mas talvez hoje precisemos perguntar: o que fizemos com esse ensino de arte obrigatório que dispõe de pouca carga horária, professores de arte sem formação ou com formação precária? Se garantir um espaço curricular foi um passo necessário, em que direção precisamos caminhar para que a arte faça diferença na escola básica e não seja apenas um "acessório" perdido entre as disciplinas consideradas estratégicas?

Buscamos pensar em uma experiência artística na escola (envolvendo práticas de criação, produção e apropriação de conhecimento) que permita experimentar o pensamento a partir de formas de saber e de poder que joguem o mínimo possível com forças de dominação e assujeitamento (FOUCAULT, 2003), fortalecendo a nossa capacidade de pensar sobre o que é feito e o que fazemos de nós agora, no presente do espaço escolar. Precisamos da arte que se distancia de uma posição de 
contemplação e que instiga a "pensar e construir a pergunta desde o interior da experiência mesma" (JODAR; GOMEZ, 2004, p. 142), abrindo-se a uma experimentação própria do exercício de modificar-se para não pensar o mesmo que antes.

\section{Ensino de arte e atitude estética}

Após a obrigatoriedade do ensino da arte na educação básica brasileira, conquista fundamental que resultou de um movimento de décadas, abrimos a questão de como temos ocupado esse espaço no currículo escolar. Interrogamos sobre o que se passa hoje no campo do ensino da arte na educação básica, talvez ainda fixada, por um lado, em uma pedagogia escolarista de perguntas e respostas prontas (JÓDAR; GOMEZ, 2004); e, por outro, em um pensamento modernista, que tende a "aplicar padrões de bom gosto e critérios de excelência artística, (...) isolada do resto da experiência, da mesma forma como, de muitas maneiras, os objetos, nos museus, estão isolados do resto da vida" (EFLAND, 2008, p. 177).

A escola contemporânea brasileira (abrigo do ensino de arte curricular) teve suas funções ampliadas: vemos, por exemplo, a "função de proteção" tentando diminuir prejuízos à criança e ao adolescente por uma condição de pobreza ou violência; ou ainda sendo local para "projetos de ampliação da jornada escolar", oportunizando que alunos possam adquirir outras experiências culturais e esportivas que não aquelas marcadas pelo conhecimento disciplinar. São práticas colocadas em funcionamento na e pela escola por ser o local marcado pela obrigatoriedade desse espaço destinado a crianças e adolescentes, como apontado por Traversini (2012, p. 176) ao tratar do "encaixe da escola com o tempo de agora".

Esses processos, pensando a partir de Foucault, estariam bem mais próximos de um assujeitamento, já que a escola vem assegurando um controle a partir do alargamento de suas funções que vão se distanciando de uma função formadora, para ir em direção à unificação de práticas, hábitos, valores e formas de pensamento. Diferente disso, seria preciso experimentar na escola a produção de um pensar que "não pode ser identificado, inocente e escolarmente" com determinados saberes e manuais imutáveis de certos rituais escolaristas (JODAR; GOMEZ, 2004, p. 142). Tal 
atitude talvez possa estar contaminada esteticamente pela arte, desafiando um modo escolarizado de pensar ou uma racionalidade advinda de um pensamento disciplinar.

No ensino da arte, esta racionalidade é reafirmada pelos programas curriculares ou pelas escolhas didáticas que ainda se regulam, por exemplo, pelo ensino de linguagens visuais e suas gramáticas e procedimentos artísticos que focam apenas no "saber" a diferença entre o "bidimensional e o tridimensional", os "períodos, estilos e movimentos da arte", não favorecendo a modificação de um pensamento, mas tão somente um aprimoramento técnico somado de conhecimentos informativos.

O giro a ser feito no pensamento sobre ensino da arte é o de permitir que nossas escolhas teóricas e didáticas favoreçam a uma atitude de disponibilidade para uma modificação constante do pensamento a partir das práticas, experimentações e conhecimentos artísticos. A abertura à experimentação do pensamento a partir das artes visuais (e também sobre elas) não pode ser operada na dimensão de uma racionalidade que de antemão já explica o que é e como deve ser feito: "Não se trata de efetuar uma razão que apreende, possui, define, nomeia, reduz ou entende a realidade. Trata-se, antes, de um jogo de mútua interferência, de composição de possibilidades que constituem sujeito e mundo" (PEREIRA, 2011, p. 114).

Para uma atitude estética na busca de novas formas de encontro entre arte e educação, se faz necessária a liberação do termo estética da tradição do século XVIII, como estudo do belo e da arte, e também de sua justificação apenas pela sensibilidade (HERMANN, 2010; PEREIRA, 2011). Trata-se de assumir a estética como uma forma de se colocar em relação com o mundo. Uma "forma mais ampla sem restringir-se a uma atividade artística, mas, aos modos de vida, à própria existência" (LOPONTE, 2013, p. 9). A estética enquanto um modo de existir não é aquela dos limites disciplinares do campo filosófico-artístico, mas a que permite um jogo de intensidade que vai muito além da matéria artística na escola.

Ao assumir o desafio de pensar de outra forma o ensino da arte, assume-se também o desafio de aproximar da escola, com mais intensidade, práticas e processos artísticos capazes de instigar uma virada no modo como temos lidado com a arte na educação. É uma escolha alinhada às práticas artísticas contemporâneas que têm 
permitido experimentações imensamente mais ricas ao desafiar o próprio campo da arte, provocando nossos modos já acostumados de ver e pensar as artes visuais (LADDAGA, 2012; BOURRIAUD, 2009).

Tais práticas artísticas contemporâneas, de artistas como Francis Alys e Monica Nador, por exemplo, podem produzir aberturas no pensamento, não oferecerendo modelos ou propostas diretamente às nossas inquietações pedagógicas, mas nos exigindo certa conversão de olhar ao que estamos tão acostumados a ver, trazendo "uma atitude de olhar, uma postura artística diante da vida e da contradição da existência" (LOPONTE, 2012, p. 9).

A aproximação de processos e práticas artísticas contemporâneas com a escola é um movimento que já vem sendo experimentado como possibilidade de desatar este modo tão alinhado das certezas pedagógicas do campo da educação. São exemplos algumas pesquisas realizadas por integrantes do grupo de pesquisa ArteVersa, que buscam, nas práticas contemporâneas de artes visuais, formas de pensamento que desloquem os modos de pensar a docência. Nessas pesquisas, a materialidade da arte e os deslocamentos provocados por processos e práticas artísticas permitiram a produção de um pensamento em torno da arte e da escola para além de domínios conhecidos. À sua maneira, trazem possibilidades de desnaturalização do olhar e de desacomodação do pensamento em torno da arte e da educação'.

Ao desafiar limites que cercam a arte na escola (e os que definem o campo artístico), apostando na experimentação e expansão da arte, expandem-se também as relações entre arte e educação, ajudando-nos a repensar práticas pedagógicas comuns de avaliar, de ensinar e de aprender. Também requer a eliminação das velhas oposições entre expressividade e técnica, tradição e inovação, argumentos que não dão conta de práticas que estão mais interessadas no movimento de pensamento e no deslocamento de subjetividades.

1 No site ArteVersa: <http://www.ufrgs.br/arteversa/wordpress/> é possível acompanhar essas pesquisas, assim como uma coleção de artistas contemporâneos que nos ajudam a pensar educação e formação. O site faz parte de ações desenvolvidas pelo grupo ArteVersa - Grupo de estudo e pesquisa em arte e docência (CNPq/UFRGS). 


\section{Ensino de arte e o político como uma possibilidade do presente}

Pensar a relação entre arte e educação básica a partir de outras perspectivas epistemológicas, artísticas e estéticas é um desafio que problematiza, simultaneamente, a nossa relação com o presente no campo da educação. Conforme aponta Tourinho (2003, p. 32-33) a respeito do ensino de arte, assistimos a uma "despolitização deste ensino" em relação aos conteúdos e práticas escolares. É uma despolitização que está implicada com as questões de gênero, etnia, classe social e idade. Segundo a autora há ainda uma "descorporificação" das alunas e alunos pela anulação do corpo como uma presença em aula. Além disso, uma "descontextualização da atividade artística" tendo em vista a adoção de certos cânones artísticos para o fazer e o apreciar arte.

É possível pensar mais sobre a descontextualização da atividade artística na escola com o que Skliar (2014) considera sobre o político, que se alinha a cada encontro entre os indivíduos e se desfaz a cada vez que os indivíduos se dispersam, se ignoram, se evadem. O político não existe antes dos indivíduos, só se dá entre as pessoas, lugar no qual se tem a chance de dar início ao novo, pois se trata da "transformação de si mesmo; (...) espaço de transformação onde a fumaceira criativa dos acontecimentos não se dissipa, mas é compartilhada, disposta em comum, aberta à conversação" (SKLIAR, 2014, p. 37).

Se o cânone artístico acompanha a arte na escola, pensemos com Agamben (2013) o que pode ser esse item exemplar. O exemplo é uma singularidade que vale para tudo, uma singularidade pura. $O$ exemplar pode apenas ser definido pelo que se diz dele, e assim, ao ser dito como abstrato, pintura, arte ou não-arte, já não o é. $O$ cânone "elimina toda a possibilidade de comunidade real", constituindo "comunidades puras que se comunicam apenas no espaço vazio do exemplo" e que têm uma vida puramente linguística (AGAMBEN, 2013, p. 18-19).

Perguntamos então, parafraseando Skliar (2014, p. 147): como chamar os alunos se eles não estão próximos de nós e se não nos aproximamos deles e se ainda nos munimos de cânones das artes? É possível acontecer uma conversa em que não 
estejamos - professores e alunos - presentes, na igualdade mais generosa de todo início e na ternura mais extrema e intensa de nossas diferenças?

Para Agamben (2012), compõe a noção moderna de arte (a partir do século $\mathrm{XVI}$ ) a diferença entre a experiência do apreciador e a experiência do criador de arte (o artista). No modelo moderno, ao apreciador foi destinada a dimensão estética da obra, que se dá por apreensão sensível do objeto artístico. O juízo crítico que mede a realidade da obra, a estrutura, a autenticidade, o contexto histórico, contribuiu para colocar, no lugar de um corpo vivo, um objeto belo para olhar "sem, no entanto, nos restituir, junto com ele nem o ramo que o sustentou, nem a terra da qual se nutriu, nem o alternar-se das estações que maturou a sua polpa" (AGAMBEN, 2012, p. 79). A avaliação (estética) da arte, assinala Agamben, começa necessariamente com o esquecimento da arte como criação.

"A crescente inocência da experiência do espectador frente ao objeto belo" (AGAMBEN, 2012, p. 23) corresponde ao processo oposto da experiência do artista, para quem não há interesse no julgamento da arte. Ao contrário, a promessa de felicidade da arte para o artista está na "realidade vivente da criação, cuja fantasia criativa não tolera nem limites nem imposições, ao passo que ao não artista resta apenas spectare, isto é, transformar-se em um partner sempre menos necessário e sempre mais passivo" (AGAMBEN, 2012, p. 40). Demarcam-se aí duas experiências distintas com a arte, forjadas na modernidade, mas vigentes ainda hoje: uma que tende ao refinamento da sensibilidade, consequentemente formando um logos sobre a arte, e outra que tende à excentricidade e à originalidade da criação, baseada na cisão com o mundo e na unidade íntima com a subjetividade.

Pensemos em como tais experiências compõem a arte na escola e nos lugares ocupados por professores e alunos em relação a ela. Certamente que algo se cria com o que já é feito; porém, com pouco espaço para a partilha do mundo entre professores e alunos e entre eles e a arte. Se a arte é aquela de itens exemplares e de posições acessíveis apenas na medida do "exercício artístico" escolarista, perguntamos com inspiração em Skliar (2014): podemos considerar que na escola estamos tratando do nosso presente, criando e conversando em igualdade e com nossas diferenças? Ou estaríamos atuando com o estabelecido no passado 
apostando, com elementos afastados de nós, num futuro que pretendemos programável e melhor? Há distâncias com a arte que precisam ser eliminadas para que o ensino de artes visuais ocorra como "uma resposta ética à existência do outro" (SKLIAR, 2014, p. 197).

Em que medida as duas experiências - criação e apreciação - constituem a experiência com arte feita na escola e como nisso se dá o espaço do político são questões a serem inseridas em nossas ponderações. Na medida em que a arte é oferecida na escola como objeto estético, talvez a estejamos inscrevendo em um logos que busca a compreensão da arte de um lugar externo a ela, a estética, enquanto elaboração teórica, mesmo que se esteja tratando sobre a arte de hoje. Ao mesmo tempo em que compreender a arte determina uma tal posição - de apreciador, intérprete -, esta se distingue do lugar de criação de arte, o que pode tanto conservar esses lugares em relação à arte, mantendo certa mística sobre a criação que acessa o artista, como, no ambiente escolar, privilegiar a racionalidade do exercício estético e simplificar o lugar da criação.

Para que a arte tenha alguma decorrência política - e por política entende-se a redistribuição das posições determinadas a uns e a outros no mundo (RANCIÈRE, 2012) - é preciso que sejam recusados "em primeiro lugar, a distância radical; em segundo, a distribuição dos papéis; em terceiro, as fronteiras entre os territórios" (RANCIÈRE, 2012, p. 21). Quanto à arte que se realiza na escola, haveríamos que pensar, em primeiro lugar, em eliminar distâncias entre arte e vida, interpretar e criar arte, ensinar e fazer arte, cânones e mundo partilhado. Em segundo lugar, pensar em redistribuir papéis: de professor, aluno, artista, espectador, teórico, crítico, aprendiz. Em terceiro lugar, recusar o que torna fixos os territórios da arte e da educação. Nos três casos, trata-se de recriações feitas com e a partir de parâmetros pertinentes ao tempo presente.

Se o que foi exposto produz, pela arte, manutenção de lugares bem delimitados, por outro lado, há promessas feitas pela arte na educação que deixam escapar o imprevisível, o não-dito das práticas que as constituem. Enquanto elas buscam assegurar a racionalidade da atividade artística e justificar pretensas contribuições, há algo a mais, que não consegue ser dito ou descrito, além de toda 
discursividade. É outro caminho a ser feito a partir da abertura de pensar a arte como atitude esteticamente contaminada e afastada de uma moral escolarista.

\section{Arte e educação no presente}

O caminho ora sugerido é desenhado a partir das transformações contemporâneas de nosso tempo em relação à escola e seus processos e políticas de formação: a crítica às ilusões da modernidade e à tentativa de modificar tudo pelo acesso ao conhecimento. Diante destas transformações, pode surgir um pensamento que considere o deslocamento e a produção de novas subjetividades, e que "implica pensar as mudanças no saber e no ensino, a descrença dos sistemas de justificação morais, políticos e educacionais" (FAVARETTO, 2010, p. 229). Trata-se de reconsiderar algumas noções que tendem a fragmentar os conhecimentos e reexaminar as justificativas que afirmam a importância e a obrigatoriedade da arte na educação.

É preciso problematizar que arte temos levado para a escola e como lá se constitui a experiência com a arte, ao mesmo tempo em que colocamos sob suspenso que noção de escola temos assumido para trabalhar com ela. $\mathrm{O}$ campo da educação é hoje marcado por muitas incertezas, "sem perspectivas diante dos inúmeros desafios do mundo atual, a escola já não satisfaz ninguém: nem alunos, nem professores, nem gestores, nem as cidades, nem o mercado" (MOSÉ, 2013, p. 54).

É a partir dessa escola que "já não satisfaz a ninguém" que precisamos pensar o encontro entre arte e educação, justificando a urgência em ultrapassar os limites de uma apropriação objetiva do conhecimento, que esvazia o exercício do pensamento para produzir o estranhamento necessário daquele que se coloca além da lógica e do conceito.

O que pulsa nas escolas, como as que foram ocupadas pelos secundaristas, é muito mais do que uma disposição para aprender novos conceitos artísticos. Há uma disposição para pensar abertamente, para duvidar das certezas impostas pelas paredes escolares, para imaginar a própria escola a partir da criação de novas metáforas. Pensar e repensar arte e educação a partir desses novos pressupostos 
torna-se mais urgente do que nunca, "a escola precisa ouvir e considerar o aluno, ter arte, filosofia e ética em todos os momentos e não se acovardar frente a perguntas difíceis, enfim, uma escola viva, alegre, corajosa, sempre aberta a novas questões" (MOSÉ, 2013, p. 84).

A atitude necessária para ocupar o ensino de arte na escola de hoje exige uma ocupação mesmo com modos de agir e de se conduzir nas artes visuais que tenham ressonância ao que se passa conosco. Não nos termos da identidade ou subjetividade individual, mas de uma existência comum a alunos e professores que partilhamos enquanto habitantes da escola. Precisamos nos desprender de protocolos de legitimação das artes, do ensino de artes visuais e da educação, não para desqualificar ou ignorá-los, mas para "em tempo real" ir corajosa e inventivamente adiante deles. Quem somos hoje, no presente, continua nos perguntando Foucault. Seguimos, pacientemente, "o trabalho sobre os nossos limites" (FOUCAULT, 2005, p. 351).

\section{Referências}

AGAMBEN, Giorgio. A comunidade que vem. Belo Horizonte: Autêntica, 2013.

AGAMBEN, Giorgio. O homem sem conteúdo. Belo Horizonte: Autêntica, 2012.

BOURRIAUD, Nicolas. Pós-produção: como a arte reprograma o mundo contemporâneo. São Paulo: Martins, 2009.

EFLAND, Arthur D. Cultura, sociedade, arte e educação num mundo pós-moderno. In: GUINSBURG, Jacob; BARBOSA, Ana Mae (Orgs.). O pós-modernismo. São Paulo: Perspectiva, 2008. p. 173-188.

FAVARETTO, Celso Fernando. Arte contemporânea e educação. Revista Iberoamericana de Educación, n. 53, p. 225-235, 2010...

FOUCAULT, Michel. O que são as luzes? In: Ditos \& Escritos, volume II: Arqueologia das ciências e história dos sistemas de pensamento. Rio de Janeiro: Forense Universitária, 2005. p. 335-351.

FOUCAULT, Michel. Poder e Saber. In: Rio de Janeiro: Forense Universitária, 2003. Ditos \& Escritos, volume IV: Estratégia, poder-saber.

HERMANN, Nadja. Autocriação e horizonte comum: ensaios sobre educação ético-estética. ljuí, RS: Unijuí, 2010.

JÓDAR, Francisco, GÓMEZ, Lucia. Experimentar o presente: sobre a conformação de novas identidades. Educação \& Realidade, vol. 29, n. 1, p. 139-153, jan./jun. 2004

LADDAGA, Reinaldo. Estética da emergência: a formação de outra cultura das artes. São Paulo: Martins Fontes, 2012.

LOPONTE, Luciana Gruppelli. Arte para a docência: estética e criação na formação docente. Archivos Analíticos de Políticas Educativas / Education Policy Analysis Archives, v. 21, n. 25, p. 1-22, mar. 2013.

MARTINS, Mirian Celeste. Arte, só nas aulas de Arte? Educação, v. 34, n. 3, p. 311-315, set./dez. 2011. MOSÉ, Viviane. A escola e os desafios contemporâneos. Rio de Janeiro: Civilização Brasileira, 2013. 
PEREIRA, Marcos Villela. Contribuições para entender a experiência estética. Revista Lusófona de Educação, n. 18, p.111-124, 2011.

RANCIÈRE, Jacques. A partilha do sensível: estética e política. São Paulo: EXO experimental; Editora 34, 2009.

RANCIÈRE, Jacques. O espectador emancipado. São Paulo: WMF Martins Fontes, 2012.

RICHTER, Ivone Mendes. Histórico da FAEB: uma perspectiva pessoal. In: BARBOSA, Ana Mae (Org.). Ensino da arte: memória e história. São Paulo: Perspectiva, 2008. p. 323-334.

SKLIAR, Carlos. Desobedecer a linguagem. Belo Horizonte: Autêntica, 2014.

TOURINHO, Irene. Transformações no ensino da arte: algumas questões para reflexão conjunta. In: BARBOSA, Ana Mae (Org.). Inquietações e mudanças no ensino da arte. São Paulo: Cortez, 2003. p. 27-34.

TRAVERSINI, Clarice Salete. O desencaixe como forma de existência da escola contemporânea. In: SARAIVA, Karla; MARCELLO, Fabiana de Amorim (Orgs.). Estudos culturais e educação: desafios atuais. Canoas: ULBRA, 2012. p. 173-186.

\section{Carmen Lúcia Capra}

Professora da Graduação no curso de Licenciatura em Artes Visuais da Universidade Estadual do Rio Grande do Sul (UERGS), Mestre e Doutoranda em Educação pelo Programa de Pós-graduação em Educação da Universidade Federal do Rio Grande do Sul (PPGEDU/UFRGS). Compõe o Núcleo Educativo do Museu de Arte do Rio Grande do Sul (MARGS) e o grupo ArteVersa - Grupo de Estudo e Pesquisa em Arte e Docência (CNPq/UFRGS).

E-mail: caluc.arte@gmail.com

Currículo: http://lattes.cnpq.br/7109666867033767

\section{Daniel Bruno Momoli}

Mestre e Doutorando em Educação pelo Programa de Pós-graduação em Educação da Universidade Federal do Rio Grande do Sul (PPGEDU/UFRGS). É docente da Universidade Alto Vale do Rio do Peixe (UNIARP) e da Faculdade Senac de Caçador (SC). Membro do Grupo de Pesquisa Arte na Pedagogia (GPAP - CNPq/MACKENZIE) e do grupo ArteVersa - Grupo de Estudo e Pesquisa sobre Arte e Docência (CNPq/UFRGS).

E-mail: danielmomoli@hotmail.com

Currículo: http://lattes.cnpq.br/7701594143194418

\section{Luciana Gruppelli Loponte}

Doutora em Educação, Professora Associada da Faculdade de Educação da Universidade Federal do Rio Grande do Sul (FACED/UFRGS), com atuação na Graduação e no Programa de Pós-Graduação em Educação, na linha de pesquisa Arte, linguagem e currículo. É líder do grupo ArteVersa - Grupo de Estudo e Pesquisa sobre Arte e Docência (CNPq/UFRGS).

E-mail: luciana.arte@gmail.com

Currículo: http://lattes.cnpq.br/8279463652781521

Recebido em 01 de julho de 2016

Aceito em 21 de agosto de 2016 